\title{
Silver Nitrate/Oligo(ethylene Oxide) Surfactant/Mesoporous Silica Nanocomposite Films and Monoliths
}

\author{
Olga Samarskaya and Ömer Dag ${ }^{1}$ \\ Department of Chemistry, Faculty of Science, Bilkent University, 06533 Ankara, Turkey
}

Received November 17, 2000; accepted February 2, 2001

\begin{abstract}
A lyotropic, liquid crystalline (LC) phase of a silver nitrate/ oligo(ethylene oxide), water, and acid mixture was used for onepot synthesis of mesoporous silica materials in which $\mathrm{Ag}^{+}$ions are uniformly distributed. Weestablished that the $\mathrm{AgN} \mathrm{O}_{3}$-to-surfactant mole ratio is very important in a $\mathbf{5 0} \mathrm{wt} \%$ surfactant/water system to preserve the hexagonal LC phase before and after the addition of the silica source. Below a $0.6 \mathrm{AgN} \mathrm{O}_{3}$-to-surfactant mole ratio, the mixture is liquid crystalline and serves as a template for silica polymerization. However, between 0.6 and $0.8 \mathrm{AgN} \mathrm{O}_{3}$-to-surfactant mole ratios, one must control the composition of the mixture during the polymerization processes. A bove a 0.8 mole ratio, $\mathrm{Ag}^{+}$ions undergo phase separation from the reaction mixture by complexing with the surfactant molecules. The resulting silica materials obtained from $\mathrm{AgN}_{3} /$ surfactant ratios above 0.8 have anisotropy but without a hexagonal mesophase. Here, we establish a $\mathrm{AgNO}_{3}$ concentration range in which the $L C$ phase is preserved to template the synthesis of mesoporous silica, and we discuss the structural behavior of the mixtures at $\mathrm{AgN}_{3} /$ surfactant mole ratios of $0.00-2.00$, using POM, PXRD, FTIR, and U V-Vis absorption spectroscopy. (c) 2001 Academic Press
\end{abstract}

Key Words: mesoporous silica films and monoliths; silver nanoparticles; liquid crystalline templating; aggregation.

\section{INTRODUCTION}

Since the discovery of mesoporous silica materials by a Mobil scientist (1), the field has been gaining increasing interest from the scientific community. One of the most important interests of the field is creating new materials not only with desirable structures but also with modified internal surfaces. These materials have some uses and functions. For instance, thiol-functionalized mesoporous silica materials have been used to demonstrate the cleaning of mercury from contaminated water (2), and the CVD of disilane, $\mathrm{Si}_{2} \mathrm{H}_{6}$, in MCM-41 thin films (3) at around 100$140^{\circ} \mathrm{C}$ gives nanoclusters of silicon, which emit in the visible region with nanosecond lifetimes (4). Syntheses of semiconductor nanoclusters (4-8), metal nanoparticles (9), and polymers (10) in the internal surfaces of inorganic mesostructures and

\footnotetext{
${ }^{1}$ To whom correspondence should be addressed. E-mail: dag@fen.bilkent. edu.tr.
}

surface modifications with different organic groups are some examples of new materials of this type in the field (11-13). These nanoparticle-loaded mesoporous materials display unique properties and may find applications in nanotechnology as sensors, catalysts, etc. $(5,6,8)$, due to the high internal surface area which dominates the properties of the materials (surface-to-bulk ratio increases dramatically).

Much effort has been devoted to preparing silver nanoparticles in both organic and inorganic environments (14-20). The use of inorganic oxide coatings (16-19) rather than organic stabilizers provides several advantages (20). There are a few approaches to producing silver nanoparticles either in the silica-coated form (21) or as silver nanoparticles containing mesoporous silica (19). The second approach was achieved through soaking the calcined mesoporous materials in the $\mathrm{AgNO}_{3}$ solution. This approach produces Ag particles of average diameter $2.5 \mathrm{~nm}$ (19). Here, we describe for the first time the incorporation of silver ions into the channels of mesoporous silica materials in their free ion form using the LC templating approach (22). This method has also been used to incorporate lithium triflate as $\mathrm{Li}^{+}$ion source for ion-conducting materials (22).

We use a lyotropic liquid crystalline phase of oligo(ethylene oxide) surfactants which house $\mathrm{Ag}^{+}$ions in the hydrophilic ethylene oxide head groups and allow $\mathrm{Ag}^{+}$ions to distribute uniformly into channels of mesoporous silica materials. It was determined that the presence of the $\mathrm{Ag}^{+}$ion does not alter the LC phase of the surfactant molecules up to an $\mathrm{Ag}^{+} /$surfactant molar ratio of 0.6-0.7 during silica polymerization. This has also been demonstrated with $\mathrm{LiCF}_{3} \mathrm{SO}_{3}$ as an ingredient. The LC phase of $\mathrm{LiCF}_{3} \mathrm{SO}_{3}$ breaks above a 0.6-0.7 surfactant-to-salt ratio, and the resulting mixture yields amorphous silica without a mesophase order (22). It was discovered by investigation that $\mathrm{CF}_{3} \mathrm{SO}_{3}^{-}$and $\mathrm{Li}^{+}$ions are mainly in the free ion form (22). In this work, we also established the conditions for $\mathrm{AgNO}_{3}$ in oligo(ethylene oxide) surfactant and used it as a template for silica polymerization in the synthesis of uniformly distributed silver-ion-containing mesoporous silica materials. Silver ions in mesoporous silica materials were later reduced to silver nanoparticles by using hydrazine in the gas phase, and the reaction was monitored with UV-Vis absorption spectroscopy. Structural and spectral changes during silica polymerization and reduction processes are discussed. 


\section{MATERIALS AND METHODS}

All the materials used in this work are Aldrich grade, and no further purification was carried out. First, the addition of 0.10$0.20 \mathrm{~g}$ of nitric acid acidified the solution of $0.00-0.30 \mathrm{~g}$ of $\mathrm{AgNO}_{3}$, which was dissolved in $2.00 \mathrm{~g}$ of distilled water. Then addition of $2.00 \mathrm{~g}$ of the surfactant $\mathrm{C}_{12} \mathrm{H}_{25}\left(\mathrm{CH}_{2} \mathrm{CH}_{2} \mathrm{O}\right)_{10} \mathrm{OH}$, $\mathrm{C}_{12} \mathrm{E}_{10}$ into this mixture and heating to $50-70^{\circ} \mathrm{C}$ allowed the mixture to homogenize. The sample at this stage is liquid crystalline and stable in the dark and in closed containers. To this mixture, preliminarily dissolved in $0.50 \mathrm{~g}$ of methanol, $2.50-$ $2.90 \mathrm{~g}$ of tetramethyl orthosilicate (TMOS) was added, and either by shaking or gentle heating, the mixture was again homogenized. At this stage, the preparation mixture is liquid. However, the hydrolysis of TMOS into various silica species and the evaporation of methanol (hydrolysis product) make the mixture thicker and allow the system to reorganize into the hexagonal mesophase. Further silica hydrolysis and polymerization/condensation take place in the solvent parts in the vicinity of the hydrophilic regions of the LC phase of the surfactant. In a few hours, samples become solid. However, the polymerization/condensation reaction continues slowly for days and months in the solid state. The silica film samples were prepared on a glass and/or a quartz and silicon(100) surface. The samples on glass slides were used for POM images; quartz-deposited samples were used for $\mathrm{N}_{2} \mathrm{H}_{4}$ reduction, which can be monitored using UV-Vis absorption spectroscopy. The thin films prepared on a silicon wafer were used for FTIR spectral measurements (note that undoped $\mathrm{Si}(100)$ is transparent to mid-IR radiation).

Polarized optical microscopy (POM) images were recorded in transmittance mode on a Meije Techno ML9400 series polarizing microscope with reflected and transmitted light illumination and by using convergent white light between parallel and crossed polarizers. FTIR spectra were recorded from film samples deposited on Si(100) using a BOMEM 102 FTIR spectrometer in transmittance mode. UV-Vis absorption spectra were recorded from film samples prepared on quartz windows using a Varian Cary 5 double-beam spectrophotometer. Powder X-ray diffraction (PXRD) patterns were obtained on a Siemens D5000 diffractometer using a high-power $\mathrm{Cu} K \alpha$ source operating at $50 \mathrm{kV} / 35 \mathrm{~mA}$.

\section{RESULTS AND DISCUSSION}

The hexagonal LC phase of the $\mathrm{C}_{12} \mathrm{E}_{10} / \mathrm{AgNO}_{3} / \mathrm{H}_{2} \mathrm{O} / \mathrm{HNO}_{3}$ mixture is preserved during polymerization of a silica source, TMOS, that was forced to undergo a hydrolysis and polymerization reaction in the hydrophilic regions of the LC phase. The liquid mixture of the ingredients solidifies in time into any shape and form, such as monoliths and films of any thickness. The POM was used at every stage of the polymerization reaction to monitor the texture of the film samples (Fig. 1). PXRD was used to establish the type of structure and degree of order of the
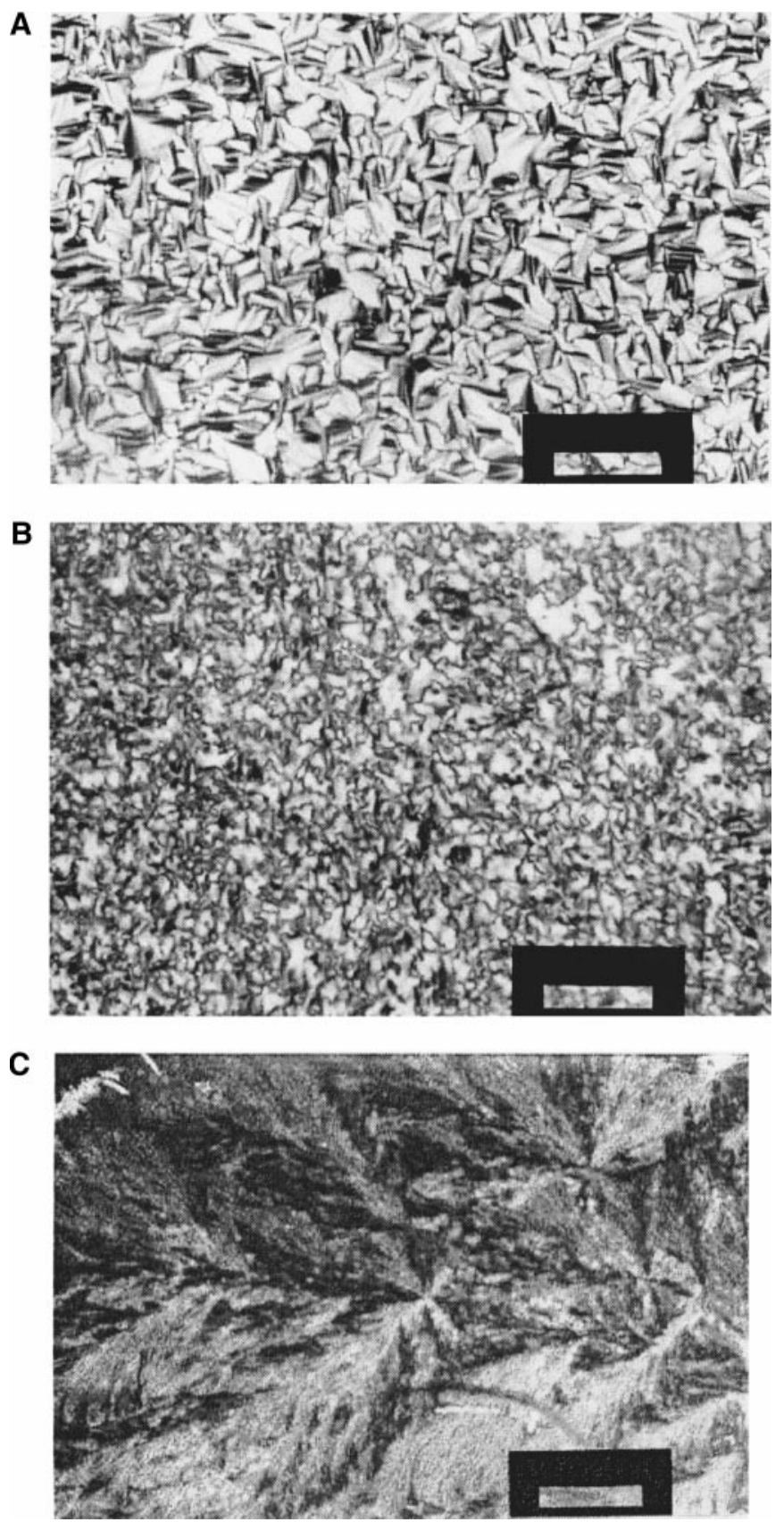

FIG. 1. Optical images taken with a polarized optical microscope showing (A) the fan texture of the hexagonal LC phase of $\mathrm{AgNO}_{3} / \mathrm{C}_{12} \mathrm{E}_{10} / \mathrm{H}_{2} \mathrm{O} / \mathrm{HNO}_{3}$; (B) the fan-like texture of the mesoporous silica film; and (C) the anisotropic brushes on the surface of the aged silica film (scale bar is $200 \mu \mathrm{m}$ ).

mesophase. FTIR spectroscopy was extensively used to illuminate the structural and phase changes.

The evaporation of methanol (a side product of the hydrolysis of TMOS) and further polymerization of the mixture resulting from reformation of the mesophase induce an optical birefringence texture. The resulting transparent, soft, but not mobile film samples (early stage of the reaction mixture) display a fan texture (Fig. 1A). Inspection of rigidified film samples by POM reveals 


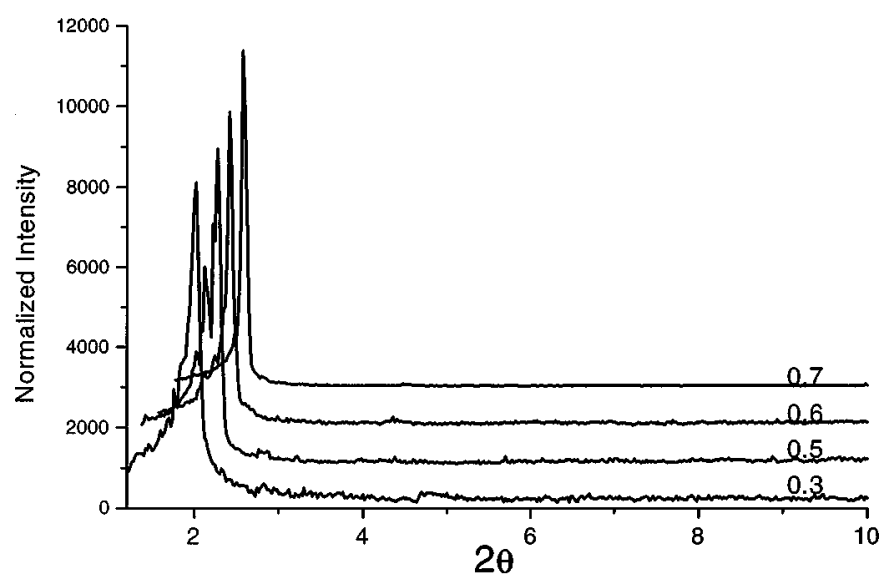

FIG . 2. Low-angle PXRD patterns for silver/surfactant/silica mesophases. $\mathrm{Ag}^{+} / \mathrm{C}_{12} \mathrm{E}_{10}$ molar ratios are indicated along the spectra.

a fan-like texture for transparent samples (Fig. 1B) and birefringence brush-like features for cloudy relatively white samples. We propose that the complexing of the $\mathrm{Ag}^{+}$ion with surfactant molecules gives $\mathrm{Ag}^{+} /$surfactant $/ \mathrm{NO}_{3}^{-}$complex aggregates, which account for the white brush structures (see text).

Powder X-ray diffraction (PXRD) data were recorded for five different samples of mesoporous silica materials with different amounts of $\mathrm{AgNO}_{3}$. The samples up to $0.7 \mathrm{AgNO}_{3}$ per surfactant display three low-angle diffraction lines at 42.2, 45.1, and $48.3 \AA$ d-spacing; no high-angle peaks are observed from this system (Fig. 2). However, the samples above $\mathrm{AgNO}_{3} /$ surfactant mole ratio 0.8 display only a very broad peak around $20^{\circ} 2 \Theta$ due to amorphous silica. It is clear from the PXRD pattern of samples of high $\mathrm{AgNO}_{3}$ /surfactant ratio (above 0.7 molar ratio) that there is no mesophase. This is also verified by POM images that do not display a fan-like bifringence texture between cross polars.

FTIR spectroscopy was extensively used in an attempt to establish the mesophase. Typical FTIR spectra of bulk template mixtures with low $\mathrm{AgNO}_{3} /$ surfactant ratios (Figs. 3a-3c), and (higher or middle) $\mathrm{AgNO}_{3}$ content (Figs. 3d, 3e) resemble one another. However, the template mixture with $\mathrm{AgNO}_{3} /$ surfactant ratio 2.00 displays drastic spectral changes (Fig. 3f). The FTIR spectra of similar surfactant molecules in both solid and LC phase have been recorded, and the assignments of the peaks in the $\delta-\mathrm{CH}_{2}$ and $\nu$ - $\mathrm{CO}$ regions have been made $(24,25)$. However, the $\delta-\mathrm{CH}_{2}$ and $\nu$-CO regions of the spectra become highly broad and hard to convolute when the $\mathrm{AgNO}_{3} /$ surfactant ratio is between 0.5 and 1.5 (Figs. 3c-3e). There are characteristic changes in spectrum $\mathrm{f}$, namely the following:

(1) The broad band of the $\mathrm{CH}_{2}$ wagging mode, which could be decomposed into two peaks at 1349 and $1363 \mathrm{~cm}^{-1}$ along with three peaks at 1130,1096 , and $1078 \mathrm{~cm}^{-1}$ in a $\mathrm{C}-\mathrm{O}-\mathrm{C}$ stretching region.

(2) The presence of three well-resolved peaks at 1467, 1446, and $1427 \mathrm{~cm}^{-1}$ referred to the $\mathrm{CH}_{2}$ scissoring mode and a peak shifted to higher energy and the split peaks at 1286, 1256, and $1234 \mathrm{~cm}^{-1}$, respectively $\left(\mathrm{CH}_{2}\right.$ twisting mode region).

All of these indicate the presence of a semicrystalline PEOtype surfactant phase and suggest an interaction of silver with the oxygen of ethylene oxide units of the surfactant molecules in a crown-like fashion. We propose here that $\mathrm{Ag}^{+}$ions undergo complexation with surfactant molecules, $\mathrm{Ag}^{+} /$surfactant $/ \mathrm{NO}_{3}^{-}$, and cause a phase separation from the mixture. The sharp IR spectral features at 1467, 1446, 1427, 1286, 1256, and $1234 \mathrm{~cm}^{-1}$ (Fig. 3f) are assigned to the mode of the complex. Dissolving $\mathrm{AgNO}_{3}$ in surfactant/water (50 wt $\%$ ) mixture and allowing water to evaporate in time checked this. It was also observed that upon drying these peaks appear, become more prominent as the concentration of salt increases, and resemble the spectra of saturated samples.

This is a likely proposal because Fragala and co-workers have investigated the process in which $\mathrm{Ag}^{+}$ions and polyethers, such as tetraglyme, 2,5,8,11,14-pentaoxatetradecane, undergo complexation to yield a crystalline complex (23). The crystal structure has been resolved, and it was determined that three of the oxygens of tetraglyme were coordinated to the $\mathrm{Ag}^{+}$ion (23). Here we also believe that coordination of the surfactant molecules occurs in a similar way, through oxygens of the ethoxy group, and results in isolation and phase separation of the $\mathrm{Ag}^{+}$ ion from the LC phase by surfactant. The concentrated samples, such as $2.0 \mathrm{AgNO}_{3} /$ surfactant (50\% water: surfactant and 2.0 $\mathrm{AgNO}_{3} /$ surfactant mole ratio), in time yield a film sample on top of the mixture. This film sample was peeled from the mixture surface, and the FTIR spectrum in the same spectral region was recorded on a $\mathrm{Si}(100)$ wafer. It was found that the peaks characteristic of the complex predominate over the entire spectra, which display peaks relatively sharper and more intense than

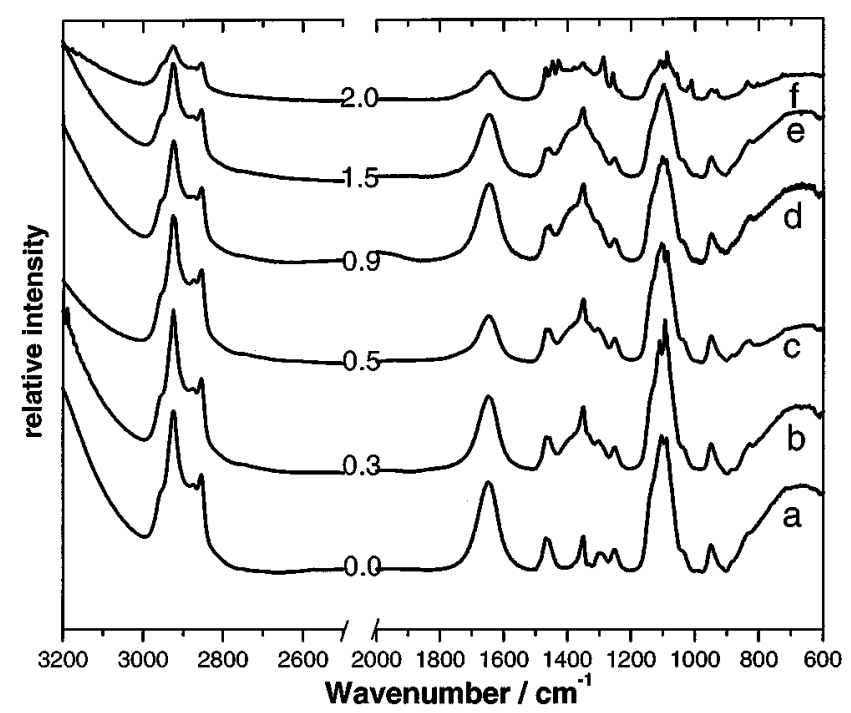

FIG. 3. FT-IR spectra of the $\mathrm{AgNO}_{3} /$ surfactant : $\mathrm{H}_{2} \mathrm{O}(50 \mathrm{wt} \%): \mathrm{HNO}_{3}$ bulk template mixture in the frequency range $3200-600 \mathrm{~cm}^{-1}$. $\mathrm{AgNO}_{3} /$ surfactant ratios are indicated along the spectra. 
those of low-concentration samples. Since the film was formed at the air/mixture interface, the $\mathrm{AgNO}_{3}$ content in the mixture and the film must be different. Further study to determine the chemical composition of the film samples is on-going.

Similar IR spectral changes were observed in the $\delta-\mathrm{CH}_{2}$ deformation region of the mesoporous silica materials at high $\mathrm{AgNO}_{3} /$ surfactant ratios (Fig. 4A). The peaks at 1467, 1446, 1427,1286 , and $1254 \mathrm{~cm}^{-1}$ dominate the spectrum of the silica sample with the $0.9 \mathrm{Ag}^{+} /$surfactant molar ratio, where we believe there is a complexing of $\mathrm{Ag}^{+}$with surfactant molecules. The complexing causes phase separation and collapse of the LC phase; as a result the template property of the mixture is lost. The FTIR spectra of the samples with low $\mathrm{AgNO}_{3}$ content where the ratio is between 0.0 and 0.7 result in typical surfactant peaks, free of the characteristic complex peaks. However, further silica polymerization, in its soft stage and in the solid state, causes contraction of the silica walls and the entire film samples; as a result some surfactant/ $/ \mathrm{ANO}_{3}$ may be squeezed out to the external surface of the materials as aggregates of the $\mathrm{Ag}^{+} /$surfactant $/ \mathrm{NO}_{3}^{-}$complexes (Fig. 4A). Note also that drying of the template mixture $\left(\mathrm{C}_{12} \mathrm{E}_{10} / \mathrm{AgNO}_{3} / \mathrm{H}_{2} \mathrm{O} / \mathrm{HNO}_{3}\right)$, even with low $\mathrm{AgNO}_{3} /$ surfactant ratios, displays signals of the complex. Keeping this in mind, it is also reasonable to assign the weak signals in the FTIR spectra of aged silica samples to the $\mathrm{Ag}^{+} /$surfactant $/ \mathrm{NO}_{3}^{-}$complex. This phase separation and complexing yield soft aggregates at the surface of the silica thin films. Note that wiping the surfaces of the film samples (with a salt-to-surfactant ratio below 0.8 ) results in changes in the FTIR spectra due to diminishing and disappearing of the complexrelated peaks. POM images of all of the film samples, which show IR spectral features characteristic of the complex also displayed brushes of aggregates on the surface of silica materials (Fig. 1C).

Pressing the silica samples with $\mathrm{KBr}$ causes an ion-exchange reaction and the formation of $\mathrm{AgBr}$, which gives a yellow color to the pellets. Upon $\mathrm{AgBr}$ formation the peaks at 1467, 1446, 1427,1286 , and $1254 \mathrm{~cm}^{-1}$ characteristic of the complex disappear and a sharp and intense peak at $1381 \mathrm{~cm}^{-1}$ appears due to the formation of $\mathrm{KNO}_{3}$ crystals (Fig. 4B). This was also investigated by making samples which contain $\mathrm{KNO}_{3}$ instead of $\mathrm{AgNO}_{3}$. Again, at low $\mathrm{KNO}_{3} /$ surfactant ratios, there is a homogeneous distribution of the ions, $\mathrm{K}^{+}$and $\mathrm{NO}_{3}^{-}$, in the silica mesophase, but at high concentrations of $\mathrm{KNO}_{3}$, the crystals of $\mathrm{KNO}_{3}$ appear at the surface of the film samples in a nice cubic and hexagonal morphology. The ion-exchange reaction results in the decomposition of the $\mathrm{Ag}^{+} /$surfactant $/ \mathrm{NO}_{3}^{-}$complex, and the related peaks disappear. However, the solubility of $\mathrm{KNO}_{3}$ in the PEO-surfactant is much lower than that of $\mathrm{AgNO}_{3}$. Also, the $\mathrm{K}^{+}$ion does not undergo complexation at higher concentrations; instead it crystallizes as $\mathrm{KNO}_{3}$, keeping the LC phase unperturbed.

The formation of the $\mathrm{Ag}^{+} /$surfactant $/ \mathrm{NO}_{3}^{-}$complex was also investigated by the reduction of $\mathrm{Ag}^{+}$ions to silver metal nanoparticles. The transparent and white samples were subjected to stepwise exposure to hydrazine vapor. The typical sequence

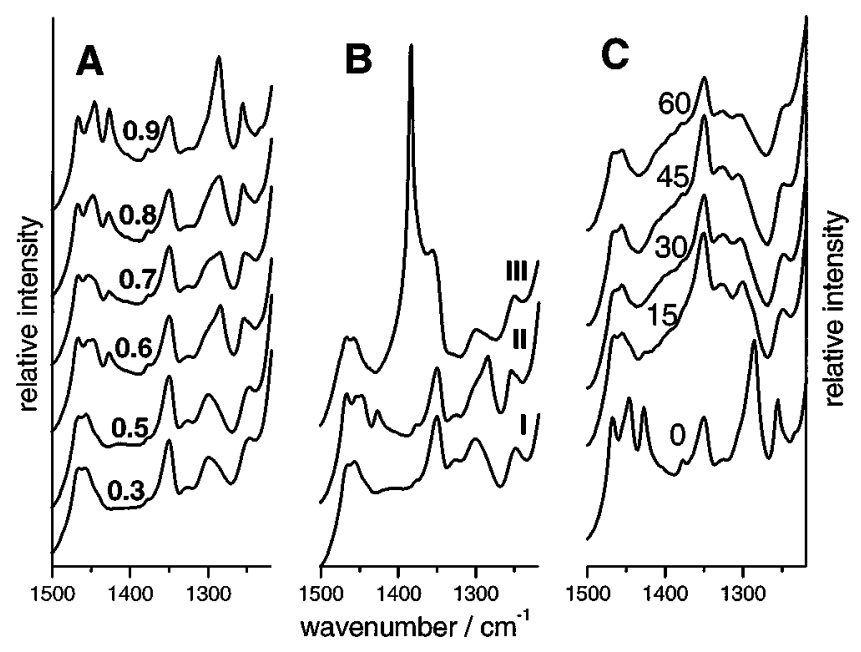

FIG. 4. FTIR spectra recorded for silica film samples on $\mathrm{Si}(100)$ in the frequency range $1500-1220 \mathrm{~cm}^{-1}$ showing (A) films aged for a month, with $\mathrm{AgNO}_{3} /$ surfactant ratios indicated along the spectra; (B) silica films with $\mathrm{AgNO}_{3} /$ surfactant ratio 0.6 (I) freshly prepared, (II) one month old, and (III) pressed in a $\mathrm{KBr}$ pellet; and (C) silica film with $\mathrm{AgNO}_{3} /$ surfactant ratio 0.9 upon prolonged reduction, where the reduction time (minutes) is indicated along the spectra.

of color changes observed was colorless/white $\rightarrow$ pale $\rightarrow$ orange $\rightarrow$ brown $\rightarrow$ black. The reduction process was monitored by UV-Vis and FTIR absorption spectroscopy and POM. In the first step of the reduction process, one observes the following: growth of a weak broad absorption band in the visible region of the spectrum between 400 and $500 \mathrm{~nm}$ due to the plasmon mode of metallic silver, disappearance of the IR spectral features $\left(\delta-\mathrm{CH}_{2}\right.$ mode) related to the complex (Fig. 4C), and changes in the morphology of the surface brushes under POM (Fig. 1C). Notice that there is a correlation between POM images and FTIR spectral features that originated from brushes at 1467 , $1446,1427,1286$, and $1254 \mathrm{~cm}^{-1}$. The peak revealed by UVVis spectroscopy blue-shifts and becomes narrower and more intense, broad overlapped bands are observed in FTIR spectra, and there is no trace of brushes in POM images upon prolonged reduction. A shiny silver mirror forms on the film surface. This thin layer can be wiped out, leaving a black film behind. Such a black silica film usually displays a plasmon band at $\sim 425 \mathrm{~nm}$, broad bands in IR spectra, and filament-like aggregates of silver in the POM images. Summarizing all of the aforementioned observations, it is clear that silver is in its ion form, is stabilized (dissolved) in surfactant and/or silica matrix, or is complexed as $\mathrm{Ag}^{+} /$surfactant $/ \mathrm{NO}_{3}^{-}$under ambient conditions. However, silver is in a metallic zero-valance state surrounded by surfactant and/or silica matrix in the samples exposed to a low atmosphere of $\mathrm{N}_{2} \mathrm{H}_{4}$. The nanometer size of the metallic silver particles accounts for the black color of the silica films. The optical properties and particle size distribution of silver nanoparticles will be discussed elsewhere.

By combining POM images and UV-Vis and FTIR spectra, we can propose that, over certain concentrations of $\mathrm{AgNO}_{3}$ in the surfactant, $\mathrm{Ag}^{+}$ions may associate with surfactant molecules 
to form complexes. We believe that this is $\mathrm{Ag}^{+} /$surfactant $/ \mathrm{NO}_{3}^{-}$, which aggregates upon the removal of water into a soft solid in the samples free of silica source and forms brush-like aggregates at the surfaces of silica materials. These aggregates at the surfaces of silica are also soft, and we believe they are not different from the complexed samples obtained from the $\mathrm{AgNO}_{3} /$ surfactant mixture.

In this paper, we have presented data relevant to the investigation of $\mathrm{Ag}^{+}$ions in the surfactant regions before and after silica addition and polymerization. It is not relevant to compare the FTIR spectral features of the soft LC phase of the mixture and the solid samples made after silica polymerization because the nature of the surfactant molecules before and after silica addition is different. However, we can safely discuss that, upon polymerization of the silica source, $\mathrm{Ag}^{+}$ions are also in their free ion states in the solid matrix, as in the case of the LC phase for low $\mathrm{AgNO}_{3} /$ surfactant ratios. Figure 4A shows FTIR spectra of samples aged for a month for different $\mathrm{AgNO}_{3} /$ surfactant ratios. Notice that there are no spectral changes for the samples obtained from $\mathrm{AgNO}_{3}$ /surfactant molar ratios up to 0.6. However, the spectra of the samples with $\mathrm{Ag}^{+} /$surfactant molar ratios of 0.6 and higher display weak complex signals. We believe that this is due to further condensation and polymerization of the silica matrix, which squeeze out some of the $\mathrm{Ag}^{+}$and surfactant to the surfaces of these samples, where they undergo drying and complexing. It was also shown by ${ }^{29} \mathrm{Si}$ MAS-NMR spectroscopy that silica polymerizations continue for more than a month. Dag et al. (22) have investigated the increase of the intensity ratio of the $\mathrm{Q}_{4}$ band to the $\left(\mathrm{Q}_{2}+\mathrm{Q}_{3}\right)$ bands (where $\mathrm{Q}_{4}$ is fully polymerized $\mathrm{SiO}_{4}$, and $\mathrm{Q}_{3}$ and $\mathrm{Q}_{2}$ are originated from $\mathrm{O}_{3} \mathrm{SiOH}$ and $\mathrm{O}_{2} \mathrm{Si}(\mathrm{OH})_{2}$ partially polymerized sides, respectively) with time over 2 months. This phenomenon was assigned to further silica polymerization over time in these types of materials (22).

\section{SU MMARY}

In this paper, we investigated the stability of the $\mathrm{AgNO}_{3}$ and $\mathrm{C}_{12} \mathrm{H}_{25}\left(\mathrm{CH}_{2} \mathrm{CH}_{2} \mathrm{O}\right)_{10} \mathrm{OH}$ system in the LC phase with $50 \mathrm{wt} \%$ water/surfactant before and after the addition of TMOS up to a $\mathrm{AgNO}_{3} /$ surfactant mole ratio of 0.6. $\mathrm{AgNO}_{3}$ and surfactant form complexes at higher mole ratios undergo phase separation from the reaction mixture. The $\mathrm{AgNO}_{3} /$ surfactant $/ \mathrm{H}_{2} \mathrm{O} / \mathrm{HNO}_{3}$ system loses both its LC and its templating properties. The materials obtained from the mixtures with $\mathrm{AgNO}_{3} /$ surfactant molar ratios 0.7 and higher are amorphous and are disordered in terms of the meso scale. The complex aggregates are soft and have no crystallographically well-defined structures. We believe that complexing is taking place due to the limited solubility of $\mathrm{AgNO}_{3}$ in pure surfactant and the coordination of $\mathrm{Ag}^{+}$ions to surfactant ethoxy groups. This has been established on the basis of our experimental observations and FTIR assignments, but there are no crystallographic data available showing the complex structure.

\section{ACK NOW LED GMENTS}

We gratefully acknowledge the Turkish Scientific Council (TÜBİTAK) for the financial support in the framework of Project TBAG 1812 and faculty development grant from Bilkent University. We also thank Dr. S. Petrov for the PXRD measurements.

\section{REFERENCES}

1. Kresge, C. T., Leonawicz, M. E., Roth, W. J., Vartuli, J. C., and Beck, J. S., Nature 359, 710 (1992)

2. Feng, X., Fryxell, G. E., Wang, L. Q., Kim, A. Y., Liu, J., and Kemner, K. M., Science 276, 923 (1997).

3. Yang, H., Coombs, N., Sokolov, I., and Ozin, G. A., Nature 381, 589 (1996).

4. Dag, Ö., Ozin, G. A., Yang, H., Reber, C., and Bussiere, G., Adv. Mater. 11, 474 (1999).

5. Moller, K., and Bein, T., Chem. Mater. 10, 2950 (1998).

6. Winkler, H., Brinkner, A., Hagen, V., Wolf, I., Schmechel, R., Seggern, H., and Fischer, R. A., Adv. Mater. 11, 1444 (1999).

7. Paralo, H., Winkler, H., Kolbe, M., Wohlfart, A., Fischer, R. A., Schmechel, R., and Seggern, H., Adv. Mater. 12, 1050 (2000).

8. Soten, I., and Ozin, G. A., Curr. Opin. Colloid Interface Sci. 4, 325 (1999).

9. L-Marzan, L. M., Giersig, M., and Mulancy, P., Chem. Commun. 9, 3408 (1996).

10. Johnson, S. A., Khushalani, D., Coombs, N., Mallouk, T. E., and Ozin, G. A., J. Mater. Chem. 1, 13 (1997).

11. Inagaki, S., Guan, S., Fukushima, Y., Ohsuna, T., and Terasaki, O., J. Am. Chem. Soc. 121, 9611 (1999).

12. Melde, B. J., Holland, B. T., Blanford, C. F., and Stein, A., Chem. Mater. 11, 3302 (1999).

13. Asefa, T., Maclachlan, M. J., Coombs, N., and Ozin, G. A., Nature 402, 867 (1999).

14. Martin, C. R., Chem. Mater. 8, 1739 (1996).

15. De, G., Gusso, M., Tapfer, L., Catalano, M., Gonella, F., Mattci, G., Mazzoldi, P., and Battaglin, G., J. Appl. Phys. 80, 6734 (1996).

16. Hardicar, V. V., and Matijević, E., J. Colloid Interface Sci. 221, 133 (2000).

17. De, G., Mattei, G., Mazzoldi, P., Sada, C., Battaglin, G., and Quaranta, A., Chem. Mater. 12, 2157 (2000).

18. Wang, L.-Z., Shi, J.-L., Zhang, W.-H., Ruan, M.-L., Yu, J., and Yan D.-S., Chem. Mater. 11, 3015 (1999).

19. Cai, W., and Zhang, L., J. Phys. Condens. Matter. 9, 7257 (1997).

20. Ung, T., Liz-Marzán, L. M., and Mulvaney, P., Langmuir 14, 3740 (1998).

21. Li, T., Moon, J., Morrone, A. A., Mecholsky, J. J., Talham, D. R., and Adair, J. H., Langmuir 15, 4328 (1999).

22. Dag, Ö., Verma, A., Ozin, G. A., and Kresge, C. T., J. Mater. Chem. 9, 1475 (1999).

23. Fragala, M. E., Malandr'no, G., and Puglisi, O., Chem. Mater. 12, 290 (2000).

24. Kimura, N., Umemura, J., and Hayashi, S., J. Colloid Interface Sci. 182, 356 (1996).

25. Madler, B., Binder, H., and Klose, G., J. Colloid Interface Sci. 202, 124 (1998). 